\title{
Identification of a promiscuous conserved CTL epitope within the
}

\section{SARS-CoV-2 spike protein}

Sheng Jiang ${ }^{\mathrm{a}, \mathrm{b}}$, Shuting $\mathrm{Wu}^{\mathrm{a}}$, Gan $\mathrm{Zhao}^{\mathrm{c}}$, Yue $\mathrm{He}^{\mathrm{c}}$, Xinrong Guo ${ }^{\mathrm{d}}$, Zhiyu Zhang ${ }^{\mathrm{c}}$, Jiawang $\mathrm{Hou}^{\mathrm{c}}$, Yuan Ding ${ }^{\mathrm{c}}$, Alex Cheng ${ }^{\mathrm{c}}$ and Bin Wang ${ }^{\mathrm{a}, \mathrm{b}, \mathrm{c}, *}$

${ }^{\mathrm{a} K e y ~ L a b o r a t o r y ~ o f ~ M e d i c a l ~ M o l e c u l a r ~ V i r o l o g y ~(M O E / N H C / C A M S), ~ S c h o o l ~ o f ~ B a s i c ~}$ Medical Sciences, Shanghai Medical College(SHMC), Fudan University \& ${ }^{b}$ National Clinical Research Center for Aging and Medicine, Huashan Hospital, Fudan University, Shanghai, China.

${ }^{\mathrm{c}}$ Advaccine Biopharmaceutics (Suzhou) Co. LTD, Jiangsu Province, China.

${ }^{\mathrm{d} C o l b y ~ C o l l e g e, ~ W a t e r v i l l e, ~ M a i n e, ~ U S A ~}$

*Corresponding Author: Bin Wang, School of Basic Medical Sciences, Fudan University, 131

Dong An Road, 409 Fuxing Building, Shanghai, China 200032. E-mail: bwang3@fudan.edu.cn 


\section{ABSTRACT}

The COVID-19 disease caused by infection with SARS-CoV-2 and its variants is devastating

3 to the global public health and economy. To date, over a hundred COVID-19 vaccines are known

4 to be under development and the few that have been approved to fight the disease are using the

5 spike protein as the primary target antigen. Although virus neutralizing epitopes are mainly

6 located within the RBD of the spike protein, the presence of T cell epitopes, particularly the CTL

7 epitopes that are likely to be needed for killing infected cells, has received comparatively little

8 attention. In this study, we predicted several potential $\mathrm{T}$ cell epitopes with web-based analytic

9 tools, and narrowed them down from several potential MHC-I and MHC-II epitopes by ELIspot

10 and cytolytic assays to a conserved MHC-I epitope. The epitope is highly conserved in current

11 viral variants including the most recent Omicron and compatible with presentation by most HLA

12 alleles worldwide. In conclusion, we identified a CTL epitope suitable for evaluating the CD8+ T

13 cell-mediated cellular response and potentially for addition into future COVID-19 vaccine

14 candidates to maximize CTL responses against SARS-CoV-2. 


\section{INTRODUCTION}

Severe Acute Respiratory Syndrome Coronavirus 2 (SARS-CoV-2) was first identified in Wuhan in early 2020, spread at unprecedented speed, and became a disaster to human beings worldwide $^{1}$. Effective vaccines, antiviral drugs, and treatments have high priorities to defend against such challenges. SARS-CoV-2 has four main structural proteins: the envelope, membrane, nucleocapsid, and spike protein that can be considered for inclusion in vaccines. The spike protein has a receptor-binding domain (RBD) that specifically binds to human angiotensin-converting enzyme 2 (hACE2) as a receptor and mediates virus entry into the host cell ${ }^{2,3}$. Neutralizing antibodies recognizing the RBD can block the spike protein from binding to the hACE2 and inhibit virus entry ${ }^{4,5}$. Therefore, spike protein has been the primary choice as the immunogen in candidate vaccines.

Although protection against disease via vaccine-induced neutralizing antibodies has been demonstrated, the elimination of SARS-CoV-2 infection within the host is also essential. The numbers of mild and asymptomatic cases are rising dramatically in recent years and such cases remain infective, prolonging viral dissemination. To eliminate the viral infection, induction of a potent antigen-specific CD8+ $\mathrm{T}$ cell response by vaccination is probably critical. To activate a viral-specific CD8+ $\mathrm{T}$ cell response, the vaccine must contain highly active major histocompatibility complex class I (MHC-I) epitopes that can be presented by MHC-I molecules to interact with $\mathrm{CD} 8+\mathrm{T}$ cell receptors $(\mathrm{TCR})$. The potentiation of viral-specific $\mathrm{CD} 8+\mathrm{T}$ cell responses is dependent upon the high affinity and avidity of MHC-I and TCR binding. There is a lack of information on the CD8+ $\mathrm{T}$ cell-recognized epitopes within the spike antigen; consequently, only overlapping peptide pools that covered the whole region of spike antigen have been used routinely to evaluate cell-mediated immunity (CMI) of a vaccine candidate ${ }^{6,7,8}$. However, a few reports had suggested that CTL epitopes are present within the spike protein ${ }^{9}$, but no detailed mapping information had been reported or potential sequences discovered. The identification of those $\mathrm{CD} 8+\mathrm{T}$ cell epitopes would provide an important tool to evaluate the $\mathrm{T}$ cell immunity in vaccinated individuals or patients and was undertaken here. 
This study utilized web-based tools to analyze the potentials for transportation associated with antigen processing (TAP) in the human MHC-I epitopes that were predicted by the Immune Epitope Database analysis (IEDB) resource $^{10}$ to be present in peptide pools covering the $n$ terminal domain (NTD) and receptor-binding domain (RBD) of the spike protein. We demonstrated that peptide 2 (YYVGYLQPRTFLLKY), although it did not give the highest score in the web-based analysis of immunogenicity, was the best epitope for inducing a robust antigenspecific IFN- $\gamma$ producing CD8 $+\mathrm{T}$ response as defined by ELIspot assay. This epitope sequence is also highly conserved among currently discovered SARS-CoV-2 variants.

\section{MATERIALS AND METHODS}

\section{Mice}

Female BALB/c mice (6-8 weeks of age) were purchased from Beijing Vital Laboratory Animal Technology Co., Ltd. (Beijing, China) and Shanghai Jiesjie Laboratory Animal Co., Ltd. (Shanghai, China), and were kept in SPF conditions. All animal experiments were approved by the Experimental Animals Committee of SHMC, and all methods were carried out in accordance with relevant guidelines and regulations. This study was carried out in compliance with the ARRIVE guidelines. All mice was sacrificed after experiment under euthanasia with Isoflurane overdose.

\section{Peptide pool derived from SARS-CoV-2 Spike protein}

The spike receptor-binding domain (RBD) peptide pool (SARS-CoV-2 spike protein 258-518aa) published previously ${ }^{7}$ was used for the study (Table 1).

\section{Immunization}

The mice were injected twice, with a two-week interval, via the intramuscular route (i.m.) with $25 \mu \mathrm{g}$ pGX9501 expressing a synthetic, optimized sequence of the SARS-CoV-2 full-length spike glycoprotein $^{7}$ and then electroporation was applied with the Cellectro2000 device. Serum samples and spleens were collected 14 days after the second immunization.

\section{IEDB analysis for SARS-CoV-2 MHC-I epitope identification}

An explorative pannnel of SARS-CoV-2-derived epitopes with strongest predicted 
affinity to MHC Class I molecules was defined by Immune Epitope Database analysis (www.IEDB.org). The selection was based on internal predicitons using NetMHCpan Version

EL4.1. all predicted epitopes with a percentile rank of $<2$ was selected for MHC-I processing analysis using MHC-NP methods. Stimultaneously, those eiptopes was analyzed in MHC-I immunogencity for checking whether the peptide sequence are consistent to the site preference of this allele. Combining results of the above three analysis methods, the peptide with a percentile rank of $<0.5$, a TAP total score of $>-1$ and a immunogencity score of $>0$ was picked up for the next ELIspot assay of T cell IFN-Y response.

\section{Cytotoxic lymphocyte (CTL) killing ability}

A single-cell suspension of splenocytes from naïve syngeneic mice was diluted to $1.5 * 10^{8} / \mathrm{ml}$ in RPMI1640 containing $10 \%$ FBS and $2 \%$ penicillin and streptomycin and pulsed at $37^{\circ} \mathrm{C}$ with or without $5 \mathrm{ug} / \mathrm{ml}$ peptides as described previously ${ }^{22}$. After $4 \mathrm{~h}$, eflour450 (eBioscience, 65-0842-85) at $5 \mathrm{mM}$ (high concentration) was used to label peptidepulsed cells at room temperature in the dark. The non-peptide-pulsed cells were labeled with a low concentration of eflour450 at $0.5 \mathrm{mM}$. After being rinsed three times with PBS, $4 * 10^{6}$ labeled and peptide-pulsed cells and an equal number of labeled non-peptide-pulsed cells were adoptively transferred by tail vein injections into mice that had previously been immunized. Six hours later, the percentage of labeled cells in spleens was detected with LSRFortessa flow cytometry (BD) and analyzed by FlowJo (TreeStar). The following formula calculated the specific cell lysis: Specific cell lysis ability $=(1-($ percentage of cells incubated with peptide/percentage of cells incubated without peptide)) $* 100 \%$.

\section{IFN-Y ELIspot}

Spleens were collected from mice individually into RPMI1640 media supplemented with 10\% FBS (Gibco) and penicillin/streptomycin and processed into single-cell suspensions. ELIspot assays were performed using Mouse IFN- $\gamma$ ELIspot plates (Dakewei Biotech Co., Ltd, 2210006). 
93 The ELIspot plates were repeat washed 5 times at RT with $100 \mu \mathrm{L}$ of PBS per well and incubated

94 with $200 \mu \mathrm{L}$ of RPMI1640 10\% FBS (R10) for $10 \mathrm{~min}$ before cell plating. Two hundred fifty

95 thousand mouse splenocytes, CD4+, or CD8+ T cells were plated into each well and stimulated

96 for $16 \mathrm{~h}$ with 15 -mer peptides from the SARS CoV-2 Spike peptide pools that overlapped by nine

97 amino acids as previously described ${ }^{7}$. Each peptide was present at a final concentration of $1 \mu \mathrm{g}$ in

$98 \quad 100 \mu \mathrm{l}$ R10 per well. The spots were developed based on the manufacturer's instructions. R10 and

99 cell stimulation cocktails (Invitrogen) were used for negative and positive controls, respectively.

100 Spots were scanned and quantified by AID ELIspot READER (AID, Germany). Spot-forming

101 units (SFU) per million cells were calculated after subtracting the negative control wells.

102 Statistical Analysis

103 The statistical analysis methods and sample sizes (n) are specified in the results section

104 or figure legends for all quantitative data. All values are reported as means \pm sem with the 105 indicated sample size. No samples are excluded from the analysis. All relevant statistical tests 106 are two-sided. P values less than 0.05 were considered statistically significant. All animal 107 studies were performed with randomized animal selection. Statistics were performed using

108 GraphPad Prism 7 software. In all data, $* \mathrm{p}<0.05, * * \mathrm{p}<0.01, * * * \mathrm{p}<0.001$, and $* * * * \mathrm{p}<0.0001$ 


\section{RESULTS}

111 Strong CD8+ CTL epitope activity is embedded in an overlapping peptide pool 1 that covers 112 the NTD and RBD region of the spike protein

113 When Balb/c mice were immunized twice with the pGX9501 DNA vaccine expressing the

114 spike protein of SARS-CoV-2, a higher level of IFN-Y expression by splenocytes was often seen

115 by the ELIspot assay when the cells were stimulated in vitro with spike peptide pool 1 (Table 1) 116 compared with pool 2 (Figure 1A). In addition, when an in vivo CTL assay was done with 117 identically immunized animals, the same peptide pool 1 gave a strong CTL response in vivo 118 (Figure 1B), suggesting that MHC-I epitope(s) were present within pool 1.

119 Screening and identification of an MHC-I epitope in peptide pool 1.

120 We placed the entire 41 peptide sequences from peptide pool 1 into the Immune Epitope 121 Database analysis (IEDB) (http://www.iedb.org/) to seek critical epitopes. An evaluation method 122 was established by integrating MHC-I binding prediction, MHC-I immunogenicity, and MHC 123 natural processing (MHC-NP) prediction from three H-2d MHC-I alleles to improve the accuracy 124 of prediction results (Table 2). In the H-2 $\mathrm{D}^{\mathrm{d}}$ allele, peptide 2 showed good MHC-I binding ability, 125 immunogenicity, and TAP ability. In the $\mathrm{H}-2 \mathrm{~K}^{\mathrm{d}}$ allele, peptide 12 showed the strongest immunogenicity, and peptide 2 presented the most potent MHC-I binding ability and TAP ability among all peptides. In the $\mathrm{H}-2 \mathrm{~L}^{\mathrm{d}}$ allele, both peptide 2 and peptide 11 showed the strongest immunogenicity, while peptide 12 emerged as having the most potent TAP ability (Figure 2A\&2B). Consequently, we used peptide 2, peptide 11, and peptide 12 to conduct an ELIspot assay of T cell IFN-Y response. 
135 (sFigure 1). Peptide 2 stimulated CD8+ T cells but not CD4+ cells, indicating that it can only be 136 presented by MHC-I (Figure 3B). To further investigate its sequence specificity, we mutated 137 several predicted anchor amino acids of peptide 2 according to the preferences of the H-2d MHC-I 138 allele $\mathrm{e}^{11-14}$. The mutated peptide 2 had a low MHC-I binding score in the IEDB prediction (Table 3) 139 and showed a significantly reduced ability to stimulate IFN- $\mathrm{Y}$ secretion by CD8+ T cells (Figure $1403 \mathrm{C})$.

\section{Analysis of peptide 2 epitope conservation and HLA distribution}

142 We used the peptide 2 sequence, YYVGYLQPRTFLLKY (amino acid 264-278), to compare 143 with current posted SARS-CoV-2 variants including variant-of-interest (VOI) and variant-of144 concern (VOC) published by WHO including the lastest o variant and observed that this sequence 145 is highly conserved (Figure 4A), and located at the end of the NTD of Spike protein and upstream 146 of the RBD (Figure 4B). The highly conserved epitopic sequence provides a useful tool for 147 evaluating the CD8+ T cell-mediated responses to vaccination in animals and humans. variable, the peptide 2 sequence that can be recognized by one population may not be recognized by others. To investigate if peptide 2 sequence could be recognized by most populations worldwide, we performed an HLA allele analysis for different regions to assess binding to one or more of the 27 prevalent MHC-I molecules, including HLA-A (01:01, 02:01, 02:03, 02:06, 03:01, 11:01, 23:01, 24:02, 26:01, 30:01, 30:02, 31:01, 32:01, 33:01, 68:01, 68:02), and HLA-B (07:02, 08:01, 15:01, 35:01, 40:01, 44:02, 44:03, 51:01, 53:01, 57:01, 58:01), as shown in Figure 4C \& Table 4. The frequency by HLAs was calculated by the online analysis tool at http://www.allelefrequencies.net/. We also evaluated the MHC-I binding ability, immunogenicity, and TAP potential of peptide 2 on different HLA alleles by IEDB (Figure 4D \& Table 5). The results indicated that peptide 2 could be recognizable by the HLA-A*02:01 allele (most in Europe and America), HLA-B*08:01 allele (in Europe and Australia), HLA-A*23:01 allele (in North 
161 (in Oceania), HLA-A*02:06 allele (in North America, North-East Asia, and Oceania), HLA-

162 A*33:01 allele (in China and Pakistan), HLA-B*35:01 allele (in Oceania), and HLA-A*03:01

163 allele (in Europe). These findings suggest that peptide 2 could be well recognized by the most

164 frequent HLA alleles of the worldwide population and can therefore be considered to be 165 promiscuous.

166

167

168

169

170

171

172

173

174

\section{DISCUSSION}

In this study, we have defined and characterized a potential CTL epitope conserved and established a BALB/c mice model to evaluate CTL responses to the spike protein of SARS-CoV-2. Furthermore, we found the peptide 2 may be well recognized by HLA alleles in most populations worldwide.

In recent studies, $\mathrm{CD} 8+\mathrm{T}$ cell immunity was found to make major contributions to the protective efficacy of SARS-CoV-2 vaccines ${ }^{15-17}$. Additionally, lymphopenia was more accentuated in symptomatic COVID-19 patients with pneumonia than in those without pneumonia, consistent with $\mathrm{T}$ cell immunity playing a protective role in pre-existing immunity against SARSCoV- $2^{17-19}$. However, the role of $\mathrm{T}$ cell immunity in the pathology of COVID-19 has not been clarified $^{20}$ and awaits further definition of $\mathrm{T}$ cell epitopes and their functions. Engineered improvements in the peptide epitopes recognized by CTL have been an essential feature of the advancements made in evaluating the cellular immunity induced by vaccines. Our work has provided a tool to monitor virus-specific CD8+ T cells and assess the contribution of CTLs to the control and the elimination of the virus.

The SARS-CoV-2 virus was found to mutate rapidly, the development of vaccines that could protect people from different variants was seen to be urgent. The neutralizing antibodies induced by vaccines were found to have variable efficacies against the different SARS-CoV-2 variants and efficacies declined over time, whereas the protection represented by $\mathrm{CD}^{+} \mathrm{T}$ cell immunity remained unchanged ${ }^{15}$. We showed here that one particular peptide from the spike protein, peptide 2 is highly conserved among variants and could be well presented by MHC-1 of all of the HLA alleles that are most frequent worldwide. Thus, the conserved peptide 2 was found suitable for 
developing peptide vaccines to induce cellular immunity against different variants of SARS-CoV-

2, including variant-of-interest (VOI) and variant-of-concern (VOC). A recent study confirmed that peptide 2 probably has a strong cell-mediated immunological function in man; a 9-mer (YLQPRTFLL) peptide that was overlapped by peptide 2 was able to induce a high level of IFN- $\gamma$ expression from PBMCs of patients who had recovered from COVID-19 and carried the HLAA*02:01 allele ${ }^{21}$

In conclusion, our study utilized web-based tools to predict human MHC-I epitopes although peptide 2 (YYVGYLQPRTFLLKY) did not give the strongest total TAP score in the prediction, the simulations indicated particularly robust antigen-specific IFN- $\gamma$-expressing CD8+ T responses overall compared to the other predicted epitope sequences. This epitope sequence is highly conservative among currently known SARS-CoV-2 variants and recognizable by most world populations. This critical MHC-I epitope sequence is located at the end of NTD of the spike protein; it can be used to assess CMI induced by a COVID-19 vaccination; it may be strategically incorporated into vaccine designs to enhance the prospect of viral elimination by vaccination.

\section{ACKNOWLEDGMENT}

This work was supported by the Chinese National Natural Science Foundation Shanghai Medical College of Fudan University for her techical supports..

207 COMPETING INTERESTS: Authors declare that they have no competing interests.

208 AUTHOR CONTRIBUTIONS: BW and SJ conceived, designed the study and drafted 209 manuscript. BW supervised the study. SJ, SW, XG, JH, YD and ZZ performed the 


\section{Tables}

Table 1. Overlapping Peptide Pool 1.

\begin{tabular}{|c|c|c|c|c|}
\hline Peptide number & Sequence & Start & End & aa \\
\hline 1 & TAGAAAYYVGYLQPR & 258 & 272 & 15 \\
\hline 2 & YYVGYLQPRTFLLKY & 264 & 278 & 15 \\
\hline 3 & QPRTFLLKYNENGTI & 270 & 284 & 15 \\
\hline 4 & LKYNENGTITDAVDC & 276 & 290 & 15 \\
\hline 5 & GTITDAVDCALDPLS & 282 & 296 & 15 \\
\hline 6 & VDCALDPLSETKCTL & 288 & 302 & 15 \\
\hline 7 & PLSETKCTLKSFTVE & 294 & 308 & 15 \\
\hline 8 & CTLKSFTVEKGIYQT & 300 & 314 & 15 \\
\hline 9 & TVEKGIYQTSNFRVQ & 306 & 320 & 15 \\
\hline 10 & YQTSNFRVQPTESIV & 312 & 326 & 15 \\
\hline 11 & RVQPTESIVRFPNIT & 318 & 332 & 15 \\
\hline 12 & SIVRFPNITNLCPFG & 324 & 338 & 15 \\
\hline 13 & NITNLCPFGEVFNAT & 330 & 344 & 15 \\
\hline 14 & PFGEVFNATRFASVY & 336 & 350 & 15 \\
\hline 15 & NATRFASVYAWNRKR & 342 & 356 & 15 \\
\hline 16 & SVYAWNRKRISNCVA & 348 & 362 & 15 \\
\hline 17 & RKRISNCVADYSVLY & 354 & 368 & 15 \\
\hline 18 & CVADYSVLYNSASFS & 360 & 374 & 15 \\
\hline 19 & VLYNSASFSTFKCYG & 366 & 380 & 15 \\
\hline 20 & SFSTFKCYGVSPTKL & 372 & 386 & 15 \\
\hline 21 & CYGVSPTKLNDLCFT & 378 & 392 & 15 \\
\hline 22 & TKLNDLCFTNVYADS & 384 & 398 & 15 \\
\hline 23 & CFTNVYADSFVIRGD & 390 & 404 & 15 \\
\hline 24 & ADSFVIRGDEVRQIA & 396 & 410 & 15 \\
\hline 25 & RGDEVRQIAPGQTGK & 402 & 416 & 15 \\
\hline 26 & QIAPGQTGKIADYNY & 408 & 422 & 15 \\
\hline 27 & TGKIADYNYKLPDDF & 414 & 428 & 15 \\
\hline 28 & YNYKLPDDFTGCVIA & 420 & 434 & 15 \\
\hline 29 & DDFTGCVIAWNSNNL & 426 & 440 & 15 \\
\hline 30 & VIAWNSNNLDSKVGG & 432 & 446 & 15 \\
\hline 31 & NNLDSKVGGNYNYLY & 438 & 452 & 15 \\
\hline 32 & VGGNYNYLYRLFRKS & 444 & 458 & 15 \\
\hline 33 & YLYRLFRKSNLKPFE & 450 & 464 & 15 \\
\hline 34 & RKSNLKPFERDISTE & 456 & 470 & 15 \\
\hline 35 & PFERDISTEIYQAGS & 462 & 476 & 15 \\
\hline
\end{tabular}




\begin{tabular}{l|c|c|c|c}
36 & STEIYQAGSTPCNGV & 468 & 482 & 15 \\
37 & AGSTPCNGVEGFNCY & 474 & 488 & 15 \\
38 & NGVEGFNCYFPLQSY & 480 & 494 & 15 \\
39 & NCYFPLQSYGFQPTN & 486 & 500 & 15 \\
40 & QSYGFQPTNGVGYQP & 492 & 506 & 15 \\
41 & PTNGVGYQPYRVVVL & 498 & 512 & 15 \\
\hline
\end{tabular}

\section{Notes:}

1. The peptides covered the entire sequence of 258-512 amino acids in the spike protein;

2. The peptides were synthesized with an average 15 amino acid length and with nine amino acids overlapping each other.

Table 2. MHC-I epitope analysis for Overlapping Peptide Pool 1.

\begin{tabular}{|c|c|c|c|c|c|c|c|c|}
\hline allele & $\begin{array}{l}\text { peptide } \\
\text { number }\end{array}$ & $\begin{array}{l}\text { MHC-I } \\
\text { binding }\end{array}$ & immunogenicity & $\begin{array}{l}\text { Proteasome } \\
\text { Score }\end{array}$ & $\begin{array}{l}\text { TAP } \\
\text { Score }\end{array}$ & $\begin{array}{l}\text { MHC } \\
\text { Score }\end{array}$ & $\begin{array}{l}\text { Processing } \\
\text { Score }\end{array}$ & $\begin{array}{l}\text { TAP } \\
\text { Total } \\
\text { Score }\end{array}$ \\
\hline $\mathrm{H}-2-\mathrm{Dd}$ & 21 & 0.01 & 0.03612 & 1.44 & 1.12 & -3.49 & 2.57 & -0.92 \\
\hline H-2-Dd & 41 & 0.04 & 0.13706 & 1.74 & 0.4 & -2.56 & 2.14 & -0.42 \\
\hline $\mathrm{H}-2-\mathrm{Dd}$ & 2 & 0.05 & 0.1573 & 1.36 & 1.07 & -3.26 & 2.43 & -0.83 \\
\hline $\mathrm{H}-2-\mathrm{Dd}$ & 26 & 0.13 & -0.02676 & 1.38 & 1.27 & -4.51 & 2.65 & -1.86 \\
\hline H-2-Dd & 9 & 0.19 & -0.11058 & 1.27 & 0.99 & -3.48 & 2.26 & -1.22 \\
\hline $\mathrm{H}-2-\mathrm{Dd}$ & 19 & 0.25 & 0.03263 & 1.33 & 1.04 & -3.45 & 2.37 & -1.08 \\
\hline $\mathrm{H}-2-\mathrm{Dd}$ & 12 & 0.29 & 0.1431 & 1.05 & 1.29 & -3.9 & 2.35 & -1.55 \\
\hline $\mathrm{H}-2-\mathrm{Dd}$ & 11 & 0.49 & 0.1386 & 1.36 & 1.21 & -4.02 & 2.57 & -1.45 \\
\hline $\mathrm{H}-2-\mathrm{Dd}$ & 32 & 0.62 & 0.0966 & 1.19 & 1.17 & -3.83 & 2.36 & -1.46 \\
\hline $\mathrm{H}-2-\mathrm{Dd}$ & 37 & 0.65 & 0.12191 & 1.38 & 1.09 & -3.76 & 2.47 & -1.29 \\
\hline H-2-Dd & 14 & 0.67 & 0.08562 & 1.39 & 0.82 & -3.76 & 2.21 & -1.55 \\
\hline $\mathrm{H}-2-\mathrm{Dd}$ & 31 & 0.7 & 0.023 & 1.31 & 1.15 & -4.17 & 2.46 & -1.71 \\
\hline H-2-Dd & 20 & 0.7 & -0.31841 & 1.47 & 1.3 & -4.6 & 2.77 & -1.83 \\
\hline $\mathrm{H}-2-\mathrm{Dd}$ & 27 & 0.89 & -0.11289 & 1.4 & 1.21 & -4.54 & 2.61 & -1.92 \\
\hline $\mathrm{H}-2-\mathrm{Dd}$ & 28 & 1.1 & -0.19576 & 0.98 & 1.12 & -4.22 & 2.1 & -2.12 \\
\hline H-2-Dd & 24 & 1.2 & 0.12947 & 1.27 & 0.71 & -4.63 & 1.98 & -2.64 \\
\hline H-2-Dd & 25 & 1.2 & -0.11559 & 1.43 & 0.15 & -4.39 & 1.58 & -2.81 \\
\hline $\mathrm{H}-2-\mathrm{Dd}$ & 18 & 1.2 & -0.22309 & 1.33 & 1.17 & -4.05 & 2.5 & -1.55 \\
\hline H-2-Dd & 40 & 1.3 & 0.1256 & 1.38 & 1.34 & -4.5 & 2.71 & -1.79 \\
\hline $\mathrm{H}-2-\mathrm{Dd}$ & 1 & 1.3 & 0.06158 & 1.24 & 1.23 & -4.32 & 2.47 & -1.85 \\
\hline $\mathrm{H}-2-\mathrm{Dd}$ & 33 & 1.5 & -0.21085 & 1.03 & 1.24 & -4.23 & 2.27 & -1.96 \\
\hline $\mathrm{H}-2-\mathrm{Dd}$ & 29 & 1.6 & 0.05792 & 1.52 & 0.5 & -4.17 & 2.02 & -2.15 \\
\hline $\mathrm{H}-2-\mathrm{Dd}$ & 30 & 1.6 & 0.05792 & 1.35 & 0.46 & -4.17 & 1.8 & -2.36 \\
\hline $\mathrm{H}-2-\mathrm{Dd}$ & 39 & 1.6 & -0.15021 & 1.25 & 1.15 & -3.84 & 2.41 & -1.44 \\
\hline $\mathrm{H}-2-\mathrm{Dd}$ & 10 & 2 & 0.01977 & 1.1 & 0.24 & -4.23 & 1.34 & -2.89 \\
\hline $\mathrm{H}-2-\mathrm{Kd}$ & 2 & 0.01 & 0.06572 & 1.24 & 0.48 & -1.78 & 1.72 & -0.06 \\
\hline $\mathrm{H}-2-\mathrm{Kd}$ & 41 & 0.05 & 0.04196 & 1.74 & 0.46 & -3.43 & 2.2 & -1.22 \\
\hline
\end{tabular}




\begin{tabular}{l|c|c|c|c|c|c|c|c} 
H-2-Kd & 9 & 0.06 & 0.12441 & 1 & 0.23 & -2.55 & 1.23 & -1.32 \\
H-2-Kd & 4 & 0.07 & 0.28634 & 1.34 & 0.37 & -2.34 & 1.71 & -0.63 \\
H-2-Kd & 3 & 0.07 & 0.05892 & 1.16 & 0.37 & -2.34 & 1.54 & -0.8 \\
H-2-Kd & 20 & 0.08 & 0.25644 & 1.45 & 0.49 & -2.65 & 1.93 & -0.71 \\
H-2-Kd & 21 & 0.08 & 0.05832 & 1.75 & 0.36 & -2.65 & 2.12 & -0.53 \\
H-2-Kd & 16 & 0.11 & 0.16858 & 1.36 & 0.4 & -2.32 & 1.77 & -0.55 \\
H-2-Kd & 40 & 0.19 & 0.0905 & 1.38 & 1.32 & -3.9 & 2.69 & -1.21 \\
H-2-Kd & 23 & 0.26 & 0.0573 & 1.31 & 0.44 & -3.18 & 1.75 & -1.43 \\
H-2-Kd & 24 & 0.61 & -0.0378 & 1.07 & 0.2 & -3.02 & 1.27 & -1.75 \\
H-2-Kd & 19 & 0.68 & 0.0279 & 1.33 & 1.2 & -3.27 & 2.52 & -0.75 \\
H-2-Kd & 10 & 0.79 & 0.034 & 1.1 & 0.23 & -3.35 & 1.33 & -2.02 \\
H-2-Kd & 12 & 0.92 & 0.34063 & 1.45 & 0.59 & -3.13 & 2.03 & -1.1 \\
H-2-Kd & 1 & 0.96 & -0.04018 & 1.24 & 1.29 & -4.51 & 2.53 & -1.98 \\
H-2-Kd & 32 & 0.99 & 0.13255 & 1.19 & 1.18 & -3.56 & 2.37 & -1.19 \\
H-2-Kd & 39 & 1.1 & 0.0801 & 1.25 & 1.31 & -3.16 & 2.56 & -0.6 \\
H-2-Kd & 31 & 1.2 & 0.1811 & 1.48 & 0.48 & -3.32 & 1.96 & -1.36 \\
H-2-Kd & 29 & 2 & 0.07062 & 1.52 & 0.5 & -3.5 & 2.02 & -1.48 \\
H-2-Kd & 30 & 2 & 0.07062 & 1.35 & 0.46 & -3.5 & 1.8 & -1.7 \\
H-2-Kd & 35 & 2 & -0.15381 & 1.42 & 1.16 & -4.52 & 2.57 & -1.95 \\
H-2-Ld & 11 & 0.06 & 0.30371 & 1.36 & 0.98 & -3.5 & 2.34 & -1.16 \\
H-2-Ld & 41 & 0.12 & -0.07228 & 1.74 & 0.35 & -3.54 & 2.09 & -1.45 \\
H-2-Ld & 21 & 0.2 & 0.05832 & 1.44 & 0.99 & -3.65 & 2.44 & -1.21 \\
H-2-Ld & 39 & 0.27 & -0.19696 & 1.25 & 0.91 & -3 & 2.16 & -0.84 \\
H-2-Ld & 12 & 0.28 & 0.09851 & 1.05 & 0.94 & -2.75 & 2 & -0.75 \\
H-2-Ld & 37 & 0.44 & 0.0801 & 1.38 & 0.99 & -4.01 & 2.37 & -1.65 \\
H-2-Ld & 2 & 0.54 & 0.28634 & 1.41 & 1.19 & -3.97 & 2.6 & -1.38 \\
H-2-Ld & 3 & 0.57 & -0.08994 & 1.52 & 1.13 & -3.97 & 2.65 & -1.32 \\
H-2-Ld & 27 & 0.77 & 0.0573 & 1.4 & 1.21 & -4.39 & 2.61 & -1.78 \\
H-2-Ld & 28 & 0.77 & 0.03448 & 0.98 & 1.12 & -4.18 & 2.1 & -2.07 \\
H-2-Ld & 19 & 0.95 & 0.11915 & 1.53 & 1.42 & -4.32 & 2.95 & -1.37 \\
H-2-Ld & 18 & 1.1 & -0.22669 & 1.33 & 1.17 & -3.82 & 2.5 & -1.32 \\
H-2-Ld & 34 & 1.9 & 0.1811 & 0.91 & 1.16 & -4.58 & 2.07 & -2.5 \\
H-2-Ld & 9 & 1.9 & -0.08994 & 1.27 & 0.99 & -4.13 & 2.26 & -1.87 \\
H-2-Ld & 38 & 2 & -0.19696 & 0.99 & 0.28 & -2.8 & 1.27 & -1.53 \\
\hline
\end{tabular}

Notes:

1. MHC-I binding score was between 0 and 2. $<0.5$ strong binder, $0.5-2$ weak binder, $>2$ non-binder.

2. A high Immunogenicity score indicates that the degree of the peptide conformity to sequence preference was good.

3. The higher the TAP total score, the higher the likelihood that the peptide will be presented after being swallowed by DCs. 
Table 3. Prediction scores of peptide 2 and mutated peptide 2

\begin{tabular}{|c|c|c|c|}
\hline & Sequence & Score & MHC-I binding \\
\hline Peptide 2 & YYVGYLQPRTFLLKY & 0.91863 & 0.01 \\
\hline Peptide 2 mut & YEVGELQDRTFELLKY & 0.025669 & $>2$ \\
\hline
\end{tabular}

Notes:

1. MHC-I binding score was between 0 and 2 , where, the $<0.5$ represents a strong binder, 0.5-2 weak binder, $>2$ non-binder.

2. Underlined amino acids were the mutated residues in the Peptide 2 mut.

Table 4. Geographic Distribution of HLA allele

\begin{tabular}{|c|c|c|c|c|}
\hline Continent & Allele & Frequency & Allele & Frequency \\
\hline \multirow[t]{3}{*}{ Australia } & HLA-A*24:02 & 0.2 & HLA-B*07:02 & 0.08 \\
\hline & HLA-A*02:01 & 0.11 & HLA-B*40:01 & 0.07 \\
\hline & HLA-A ${ }^{*} 11: 01$ & 0.08 & & \\
\hline \multirow[t]{4}{*}{ Europe } & HLA-A*02:01 & 0.26 & HLA-B*07:02 & 0.08 \\
\hline & HLA-A*01:01 & 0.12 & HLA-B*08:01 & 0.07 \\
\hline & HLA-A*03:01 & 0.12 & HLA-B*51:01 & 0.07 \\
\hline & HLA-A*24:02 & 0.1 & & \\
\hline \multirow[t]{3}{*}{ North Africa } & $\mathrm{HLA} \mathrm{A}^{*} 02: 01$ & 0.12 & HLA-B*51:01 & 0.07 \\
\hline & & & HLA-B*08:01 & 0.05 \\
\hline & & & HLA-B*35:01 & 0.05 \\
\hline \multirow[t]{6}{*}{ North America } & HLA-A*02:01 & 0.2 & HLA-B*35:01 & 0.08 \\
\hline & HLA-A ${ }^{\star} 24: 02$ & 0.12 & HLA-B*07:02 & 0.07 \\
\hline & & & HLA-B*08:01 & 0.05 \\
\hline & & & HLA-B*15:01 & 0.05 \\
\hline & & & HLA-B*44:03 & 0.05 \\
\hline & & & HLA-B*51:01 & 0.05 \\
\hline \multirow[t]{5}{*}{ North-East Asia } & HLA-A*24:02 & 0.22 & HLA-B*51:01 & 0.08 \\
\hline & HLA-A*02:01 & 0.14 & HLA-B*35:01 & 0.07 \\
\hline & & & HLA-B*15:01 & 0.07 \\
\hline & & & HLA-B*44:03 & 0.06 \\
\hline & & & HLA-B*07:02 & 0.05 \\
\hline \multirow[t]{2}{*}{ Oceania } & HLA-A*24:02 & 0.3 & HLA-B*35:01 & 0.15 \\
\hline & HLA-A*11:01 & 0.15 & & \\
\hline \multirow{2}{*}{$\begin{array}{c}\text { South and } \\
\text { Central America }\end{array}$} & HLA-A*02:01 & 0.2 & HLA-B*40:01 & 0.25 \\
\hline & $H L A-A^{*} 24: 02$ & 0.14 & & \\
\hline \multirow[t]{3}{*}{ South Asia } & HLA-A*11:01 & 0.13 & & \\
\hline & HLA-A*01:01 & 0.1 & & \\
\hline & HLA-A*24:02 & 0.1 & & \\
\hline
\end{tabular}




\begin{tabular}{|c|c|c|c|c|}
\hline \multirow[t]{2}{*}{ South-East Asia } & HLA-A ${ }^{*} 11: 01$ & 0.2 & HLA-B* $40: 01$ & 0.1 \\
\hline & HLA-A*24:02 & 0.15 & HLA-B*58:01 & 0.06 \\
\hline \multirow{2}{*}{$\begin{array}{c}\text { Sub-Saharan } \\
\text { Africa }\end{array}$} & HLA-A*23:01 & 0.11 & HLA-B*07:02 & 0.06 \\
\hline & HLA-A*02:01 & 0.1 & HLA-B*08:01 & 0.05 \\
\hline \multirow[t]{2}{*}{ Western Asia } & HLA-A*02:01 & 0.15 & & \\
\hline & HLA-A*01:01 & 0.1 & & \\
\hline
\end{tabular}

Notes

1. Frequency means the proportion of HLA allele present in the survey population. This table only shows the alleles for which frequency was higher than 0.05 in the continent.

Table 5. Human MHC-I epitope analysis for peptide 2

\begin{tabular}{|c|c|c|c|c|c|c|c|c|}
\hline Allele & $\begin{array}{l}\text { Peptide } \\
\text { number }\end{array}$ & $\begin{array}{l}\text { MHC-I } \\
\text { binding }\end{array}$ & Immunogenicity & $\begin{array}{l}\text { Proteasome } \\
\text { Score }\end{array}$ & $\begin{array}{l}\text { TAP } \\
\text { Score }\end{array}$ & $\begin{array}{l}\text { MHC } \\
\text { Score }\end{array}$ & $\begin{array}{l}\text { Processing } \\
\text { Score }\end{array}$ & $\begin{array}{c}\text { TAP } \\
\text { Total } \\
\text { Score }\end{array}$ \\
\hline HLA-A*02:01 & 2 & 0.02 & 0.18048 & 1.39 & 0.39 & -0.66 & 1.78 & 1.12 \\
\hline HLA-B*08:01 & 2 & 0.02 & 0.14268 & 1.39 & 0.39 & -1.31 & 1.78 & 0.47 \\
\hline HLA-A*23:01 & 2 & 0.03 & 0.19092 & 1.36 & 1.13 & -1.38 & 2.5 & 1.12 \\
\hline HLA-A*02:03 & 2 & 0.03 & 0.18064 & 1.39 & 0.39 & -0.91 & 1.78 & 0.87 \\
\hline HLA-A*24:02 & 2 & 0.04 & 0.19092 & 1.36 & 1.13 & -1.67 & 2.5 & 0.83 \\
\hline HLA-A*02:06 & 2 & 0.04 & 0.18064 & 1.39 & 0.39 & -0.96 & 1.78 & 0.82 \\
\hline HLA-A*33:01 & 2 & 0.09 & 0.18048 & 0.76 & 0.68 & -1.13 & 1.43 & 0.3 \\
\hline HLA-B*35:01 & 2 & 0.1 & 0.18064 & 1.41 & 1.19 & -2.35 & 2.6 & 0.25 \\
\hline HLA-A*03:01 & 2 & 0.12 & 0.18064 & 0.89 & 0.18 & -1.35 & 1.06 & -0.29 \\
\hline HLA-A*32:01 & 2 & 0.21 & 0.18064 & 1.39 & 0.39 & -2.21 & 1.78 & -0.43 \\
\hline HLA-B*53:01 & 2 & 0.21 & 0.18064 & 1.41 & 1.19 & -3.4 & 2.6 & -0.8 \\
\hline HLA-A*01:01 & 2 & 0.23 & 0.18424 & 1.41 & 1.24 & -2.91 & 2.65 & -0.26 \\
\hline HLA-B*15:01 & 2 & 0.29 & 0.18064 & 1.41 & 1.28 & -1.79 & 2.69 & 0.89 \\
\hline HLA-A*30:02 & 2 & 0.35 & 0.19092 & 1.41 & 1.28 & -2.29 & 2.69 & 0.4 \\
\hline HLA-A*31:01 & 2 & 0.45 & 0.18064 & 0.76 & 0.68 & -1.9 & 1.43 & -0.47 \\
\hline HLA-A*26:01 & 2 & 0.52 & 0.18048 & 1.41 & 1.28 & -4.14 & 2.69 & -1.45 \\
\hline HLA-A*11:01 & 2 & 0.53 & 0.18064 & 0.89 & 0.18 & -1.63 & 1.06 & -0.57 \\
\hline HLA-B*58:01 & 2 & 0.55 & 0.18064 & 1.36 & 1.06 & -3.33 & 2.42 & -0.9 \\
\hline HLA-B*57:01 & 2 & 0.56 & 0.18064 & 1.36 & 1.07 & -3.39 & 2.43 & -0.95 \\
\hline HLA-B ${ }^{\star} 51: 01$ & 2 & 0.65 & 0.18064 & 1.41 & 1.28 & -4.36 & 2.69 & -1.67 \\
\hline HLA-B*07:02 & 2 & 0.72 & 0.18064 & 1.41 & 1.19 & -3.75 & 2.6 & -1.15 \\
\hline HLA-A*30:01 & 2 & 0.73 & 0.18424 & 1.41 & 1.28 & -3.73 & 2.69 & -1.05 \\
\hline HLA-A*68:02 & 2 & 1.4 & 0.18064 & 1.39 & 0.39 & -3.11 & 1.78 & -1.33 \\
\hline HLA-B*44:03 & 2 & 1.6 & 0.18424 & 1.41 & 1.28 & -4.01 & 2.69 & -1.33 \\
\hline HLA-B*44:02 & 2 & 1.9 & 0.18424 & 1.41 & 1.28 & -4.16 & 2.69 & -1.47 \\
\hline HLA-A*68:01 & 2 & 2.4 & 0.18064 & 0.76 & 0.68 & -2.33 & 1.43 & -0.9 \\
\hline HLA-B*40:01 & 2 & 3.1 & 0.18048 & 1.41 & 1.28 & -4.44 & 2.69 & -1.75 \\
\hline
\end{tabular}

\section{Notes}


4. MHC-I binding score was between 0 and 2. $<0.5$ strong binder, 0.5-2 weak binder, $>2$ non-binder.

5. The high Immunogenicity score means the degree of the peptide conformity to sequence preference was good.

6. The higher the TAP total score, the higher the likelihood that the peptide will be presented after being swallowed by DCs. 


\section{Figure Legends}

Figure 1. Peptide pool 1 Induced strong $T$ cell responses in BALB/c mice post-administration of pGX9501

Balb/c mice ( $\mathrm{n}=5$ /group) were immunized twice two weeks apart with $25 \mu \mathrm{g}$ pGX9501 or pVAX1 (empty vector). T cell responses were analyzed on day 14 after the second injection. (A) Splenocytes were harvested and T cell responses were measured by IFN- $\gamma$ ELIspot after stimulation for $20 \mathrm{~h}$ with overlapping peptide pools 1 or 2 . (B) Antigenspecific cytotoxic lymphocyte (CTL) killing activity was evaluated by an in vivo CTL assay. Target cells at $4 * 10^{6} / \mathrm{ml}$ from naïve mice were peptide-pulsed with pool 1 then labeled with a high concentration of eFlour450 in vitro Control cells were non-peptide-pulsed cells and labeled with a low concentration of eFluor450.The cells were mixed and transferred i.v. into immunized mice. After 5 h, splenocytes were harvested and the intensity of eFlour450 peptide labeled target cells was compared with the non-peptide-labeled negative control cells by flow cytometry.

\section{Figure 2. IEDB prediction scores of peptides in pool 1}

CTL epitope peptides were screened by integrating MHC-I binding prediction, MHC-I immunogenicity (A), and MHC-NP (B) prediction from three H-2d MHC-I alleles.

Figure 3. Peptide 2 is identified as the CD8+ CTL epitope

BALB/c mice were immunized with the pGX9501. Splenocytes were obtained and specific Tcell induction was analyzed with IFN-y ELIspot, using stimulation with the indicated peptides. (A) Splenocytes, (B) CD4+, and (C) CD8+ T cells. . 
Figure 4. Conserved Sequence \& MHC-I HLA Analysis of peptide 2

(A) The sequence of peptide 2 was highly conserved in the 11 virus variants that have been identified as the variants of interest and the variants of concern, as published by WHO.

(B)The position of the peptide 2 ( yellow marked ) in the stereoscopic structure of the spike protein. (C) The global distribution of HLA alleles. (D) Analysis of peptide 2 by integration of MHC-I binding prediction, MHC-I immunogenicity, and MHC-NP prediction from the HLA alleles. 


\section{References:}

1 Li, Q. et al., Early Transmission Dynamics in Wuhan, China, of Novel Coronavirus-Infected Pneumonia. The New England journal of medicine 3821199 (2020).

2 Pal, M., Berhanu, G., Desalegn, C. \& Kandi, V., Severe Acute Respiratory Syndrome Coronavirus-2 (SARS-CoV-2): An Update. Cureus 12 e7423 (2020).

3 Sakamoto, A. et al., ACE2 (Angiotensin-Converting Enzyme 2) and TMPRSS2 (Transmembrane Serine Protease 2) Expression and Localization of SARS-CoV-2 Infection in the Human Heart. Arteriosclerosis, Thrombosis, and Vascular Biology (2020).

4 Huang, W. C. et al., SARS-CoV-2 RBD Neutralizing Antibody Induction is Enhanced by Particulate Vaccination. ADV MATER 322005637 (2020).

5 Kreye, J. et al., A SARS-CoV-2 neutralizing antibody protects from lung pathology in a COVID19 hamster model. bioRxiv (2020).

$6 \mathrm{Wu}$, S. et al., A single dose of an adenovirus-vectored vaccine provides protection against SARSCoV-2 challenge. NAT COMMUN 11 (2020).

7 Smith, T. et al., Immunogenicity of a DNA vaccine candidate for COVID-19. NAT COMMUN 11 2601 (2020).

8 Lu, J. et al., A COVID-19 mRNA vaccine encoding SARS-CoV-2 virus-like particles induces a strong antiviral-like immune response in mice. CELL RES 30936 (2020).

9 Muraoka, D. et al., Identification of a dominant CD8(+) CTL epitope in the SARS-associated coronavirus 2 spike protein. VACCINE 387697 (2020).

10 Reynisson, B., Alvarez, B., Paul, S., Peters, B. \& Nielsen, M., NetMHCpan-4.1 and NetMHCIIpan-4.0: improved predictions of $\mathrm{MHC}$ antigen presentation by concurrent motif deconvolution and integration of MS MHC eluted ligand data. NUCLEIC ACIDS RES 48 W449 (2020). 11 Balendiran, G. K. et al., The three-dimensional structure of an H-2Ld-peptide complex explains the unique interaction of Ld with beta-2 microglobulin and peptide. Proc Natl Acad Sci U S A 946880 (1997).

12 Speir, J. A. et al., Structural basis of 2C TCR allorecognition of H-2Ld peptide complexes. Immunity (Cambridge, Mass.) 8553 (1998).

13 Suri, A., Walters, J. J., Levisetti, M. G., Gross, M. L. \& Unanue, E. R., Identification of naturally processed peptides bound to the class I MHC molecule H-2Kd of normal and TAP-deficient cells. EUR J IMMUNOL 36544 (2006).

14 CORR, M., BOYD, L. F., PADLAN, E. A. \& MARGULIES, D. H., H-2Dd exploits a four residue peptide binding motif. The Journal of experimental medicine 1781877 (1993).

15 Alter, G. et al., Immunogenicity of Ad26.COV2.S vaccine against SARS-CoV-2 variants in humans. Nature (London) (2021).

16 DiPiazza, A. T., Graham, B. S. \& Ruckwardt, T. J., T cell immunity to SARS-CoV-2 following natural infection and vaccination. Biochem Biophys Res Commun 538211 (2021).

17 Zhang, G. et al., Analysis of clinical characteristics and laboratory findings of 95 cases of 2019 novel coronavirus pneumonia in Wuhan, China: a retrospective analysis. RESP RES 2174 (2020).

18 Bonifacius, A. et al., COVID-19 immune signatures reveal stable antiviral T cell function despite 
declining humoral responses. IMMUNITY 54340 (2021).

19 Wang, F. et al., Characteristics of Peripheral Lymphocyte Subset Alteration in COVID-19 Pneumonia. The Journal of infectious diseases 2211762 (2020).

20 Muraoka, D. et al., Identification of a dominant CD8(+) CTL epitope in the SARS-associated coronavirus 2 spike protein. VACCINE 387697 (2020).

21 Agerer, B. et al., SARS-CoV-2 mutations in MHC-I-restricted epitopes evade CD8+ cell responses. Science Immunology 6 g6461 (2021).

22 Clemente, T., Dominguez, M. R., Vieira, N. J., Rodrigues, M. M. \& Amarante-Mendes, G. P., In vivo assessment of specific cytotoxic T lymphocyte killing. METHODS 61105 (2013). 


\section{Figure 1}

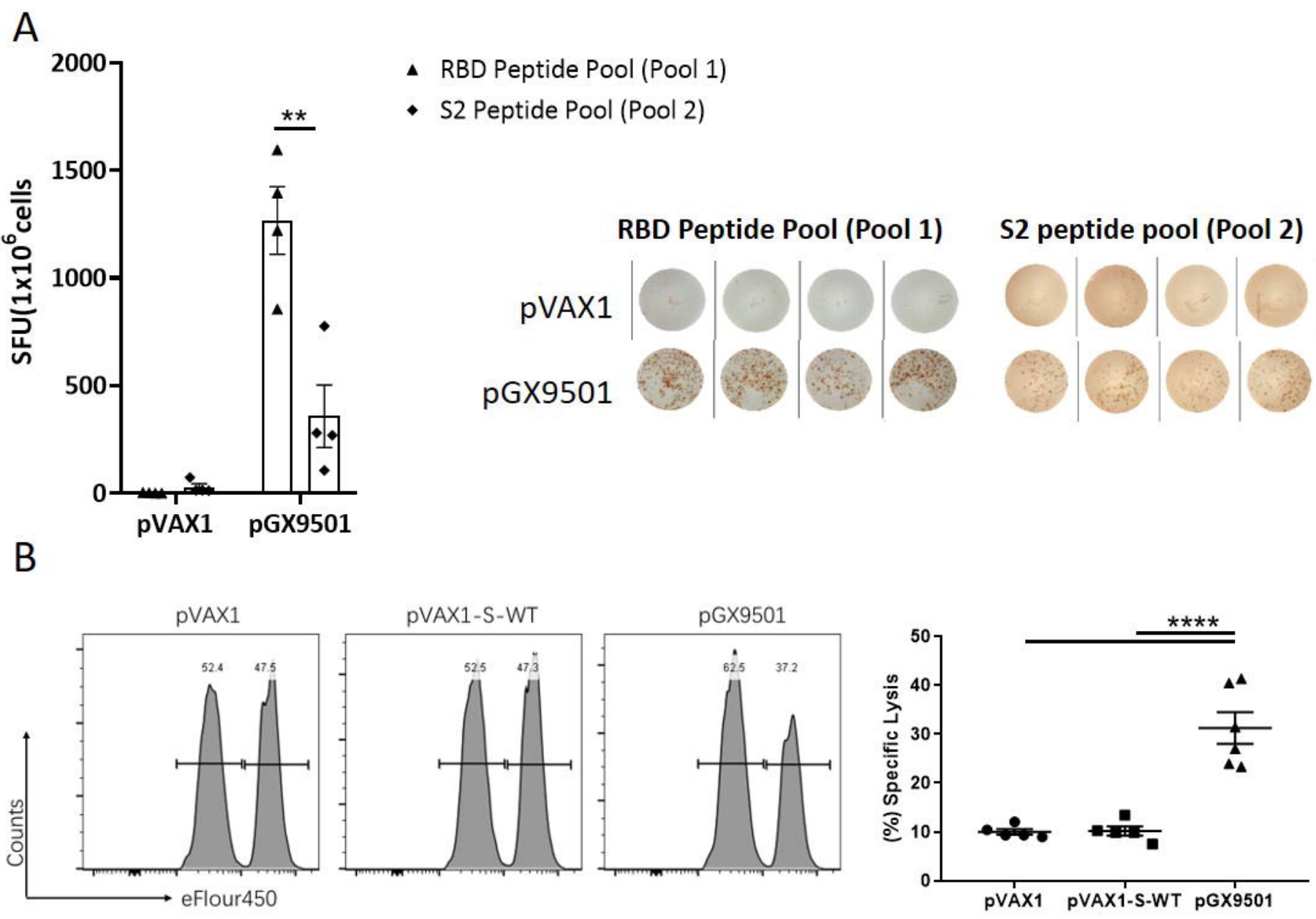


Figure 2

A
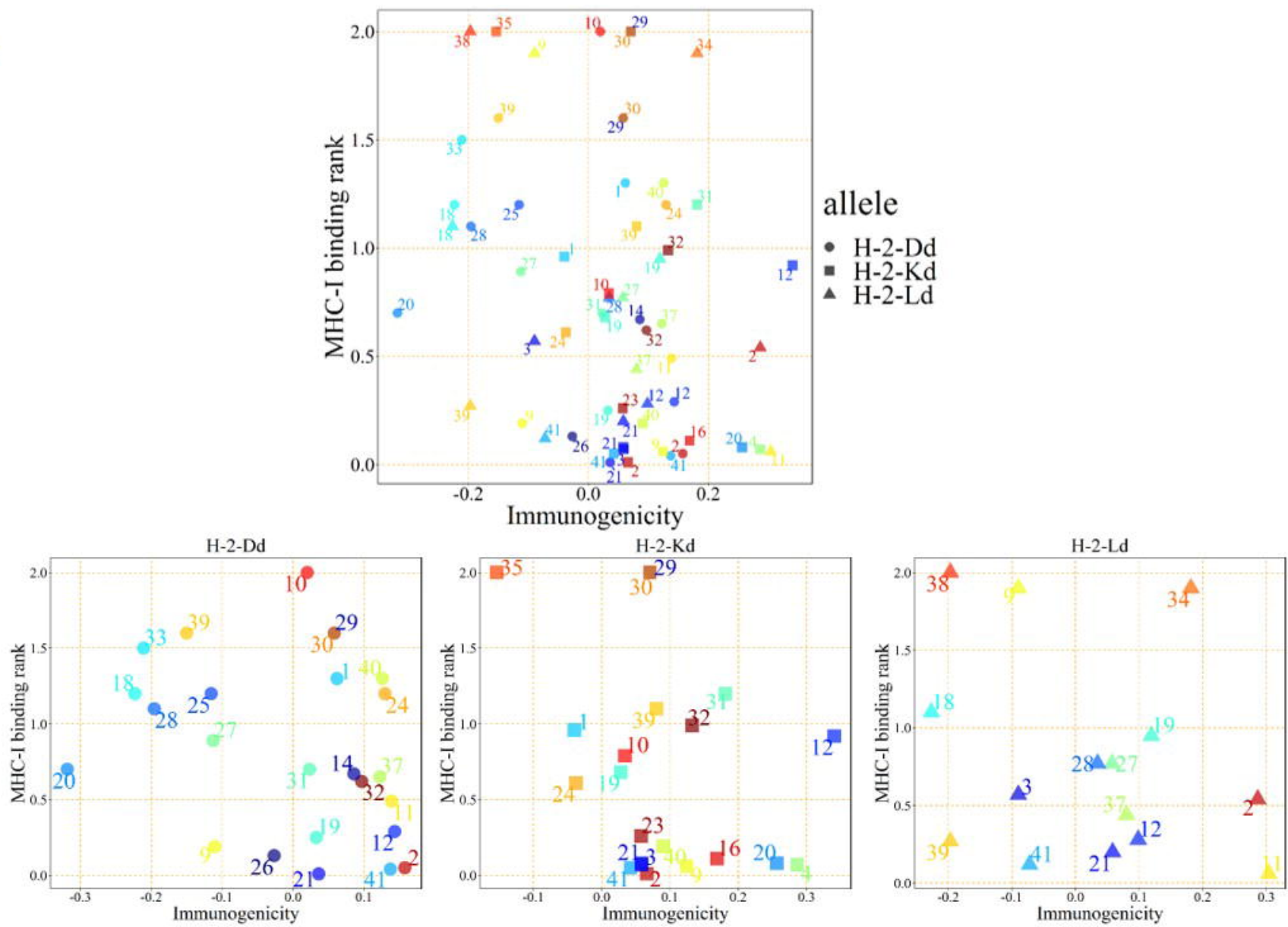

B
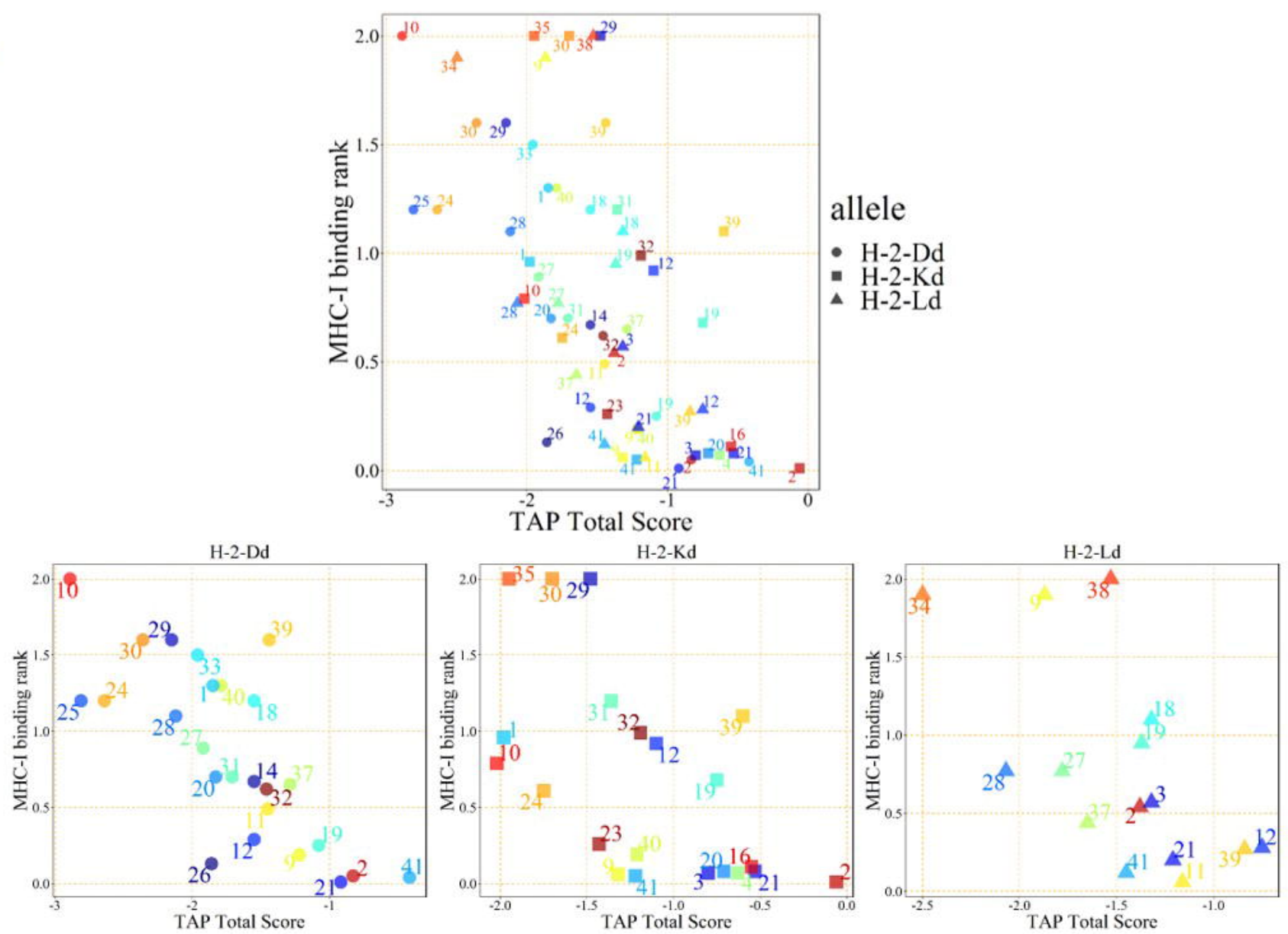
Figure 3
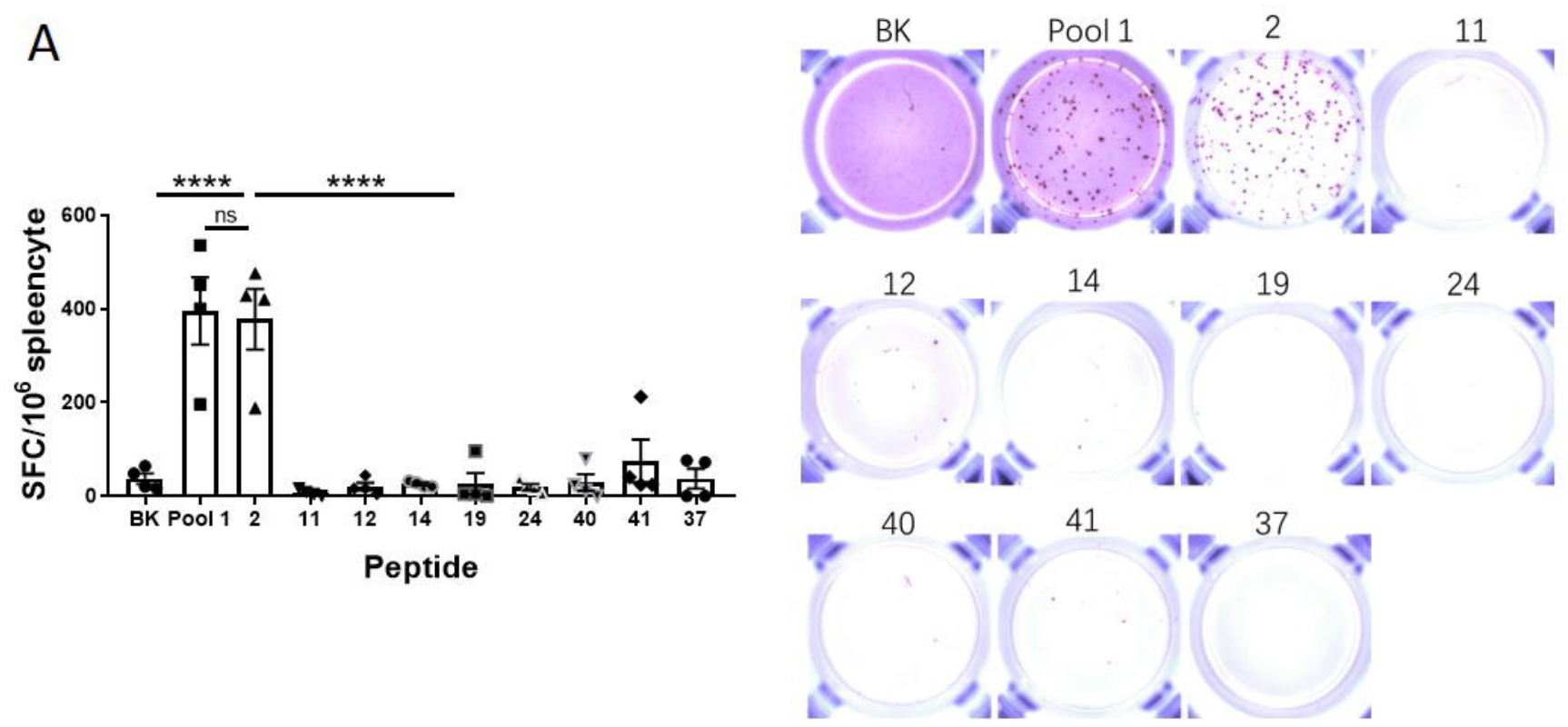

B
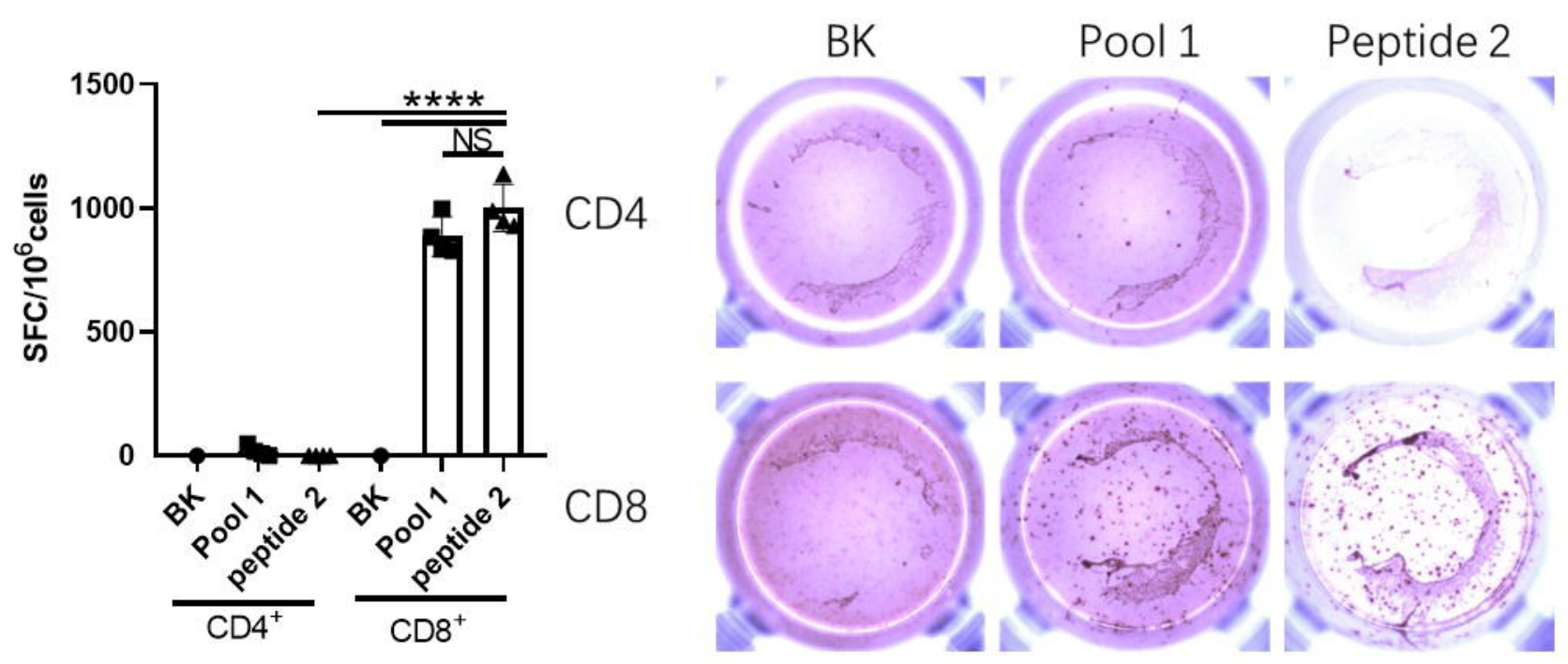

C

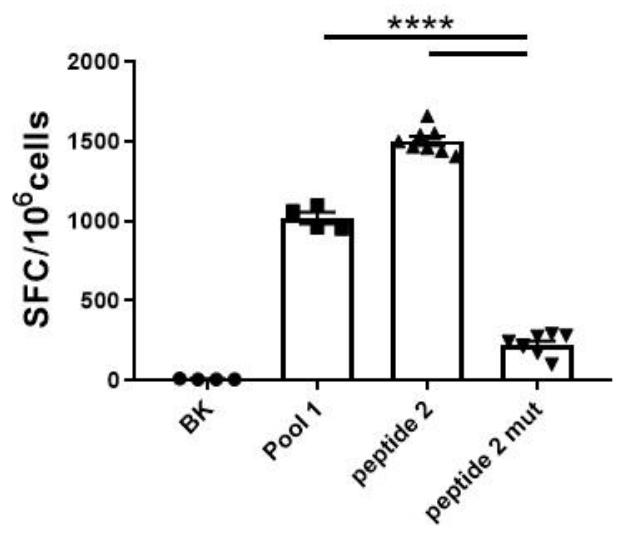

BK Pool 1 Peptide 2 Peptide 2 mut

CD8

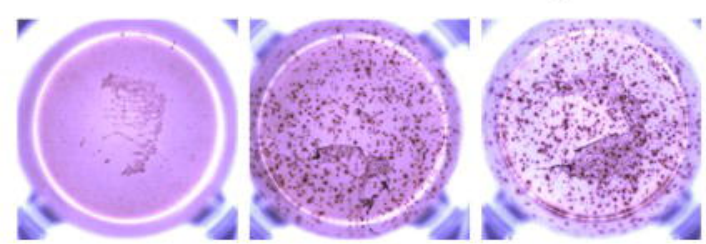




\section{Figure 4}

\section{A}

variant of interest, VO

variant of concern, VOC
Variant Pango lineage B.1.429

B.1.427

P.2

B.1.525

B.1.526

B.1.617.1

C. 37

B1.621

B1.1.7

B.1.351

P.1

B.1.617.2

B.1.1.539
TAGAAAYYVGYLQPRTFLLKYNENGTITDAVDCALDPLSETKCTLKSFTVEKGIYQTSNFRVQPTE TAGAAAYYVGYLQPRTFLLKYNENGTITDAVDCALDPLSETKCTLKSFTVEKG IYQTSNFRVQPTE TAGAAAYYVGYLQPRTFLLKYNENGTITDAVDCALDPLSETKCTLKSFTVEKG IYQTSNFRVQPTE TAGAAAYYVGYLQPRTFLLKYNENGTITDAVDCALDPLSETKCTLKSFTVEKG IYQTSNFRVQPTE TAGAAAYYVGYLQPRTFLLKYNENGTITDAVDCALDPLSETKCTLKSFTVEKG IYQTSNFRVQPTE TAGAAAYYVGYLQPRTFLLKYNENGT ITDAVDCALDPLSETKCTLKSFTVEKGIYQTSNFRVQPTE TAGAAAYYVGYLQPRTFLLKYNENGTITDAVDCALDPLSETKCTLKSFTVEKG IYQTSNFRVQPTE TAGAAAYYVGYLQPRTFLLKYNENGTITDAVDCALDPLSETKCTLKSFTVEKGIYQTSNFRVQPTE TAGAAAYYVGYLQPRTFLLKYNENGT ITDAVDCALDPLSETKCTLKSFTVEKG IYQTSNFRVQPTE TAGAAAYYVGYLQPRTFLLKYNENGTITDAVDCALDPLSETKCTLKSFTVEKG IYQTSNFRVQPTE TAGAAAYYVGYLQPRTFLLKYNENGTITDAVDCALDPLSETKCTLKSFTVEKGIYQTSNFRVQPTE TAGAAAYYVGYLQPRTFLLKYNENGTITDAVDCALDPLSETKCTLKSFTVEKGIYQTSNFRVQPTE TAGAAAYYVGYLQPRTFLLKYNENGTITDAVDCALDPLSETKCTLKSFTVEKG IYQTSNFRVQPTE TAGAAAYYVGYLQPRTFLLKYNENGT ITDAVDCALDPLSETKCTLKSFTVEKG IYQTSNFRVQPTE

$\mathrm{B}$
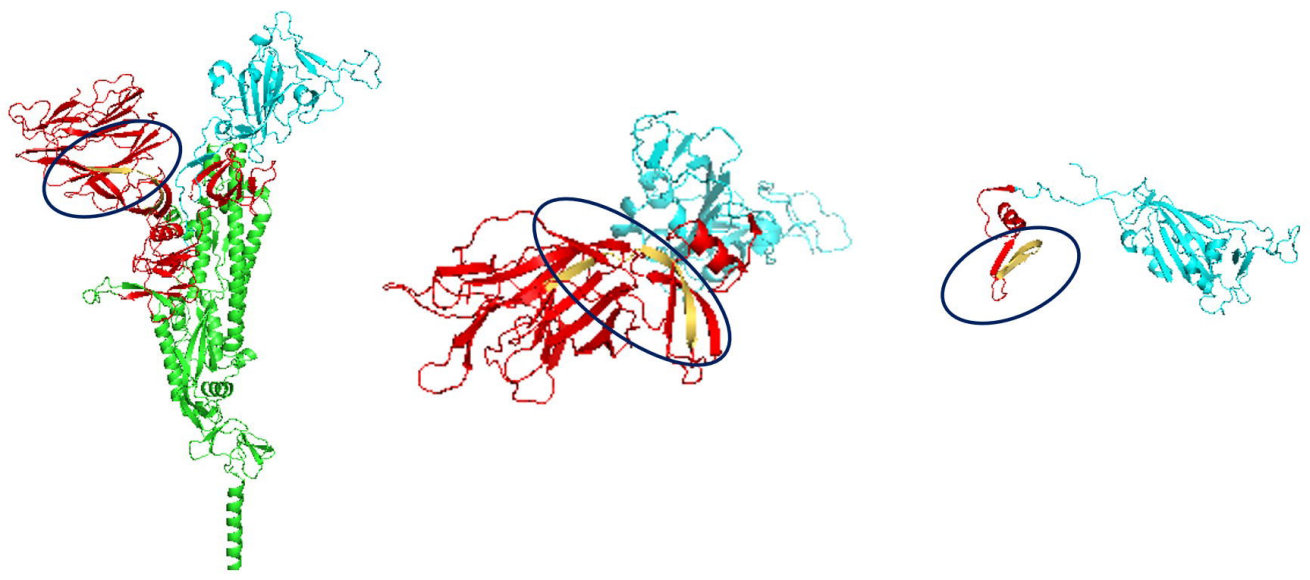

C

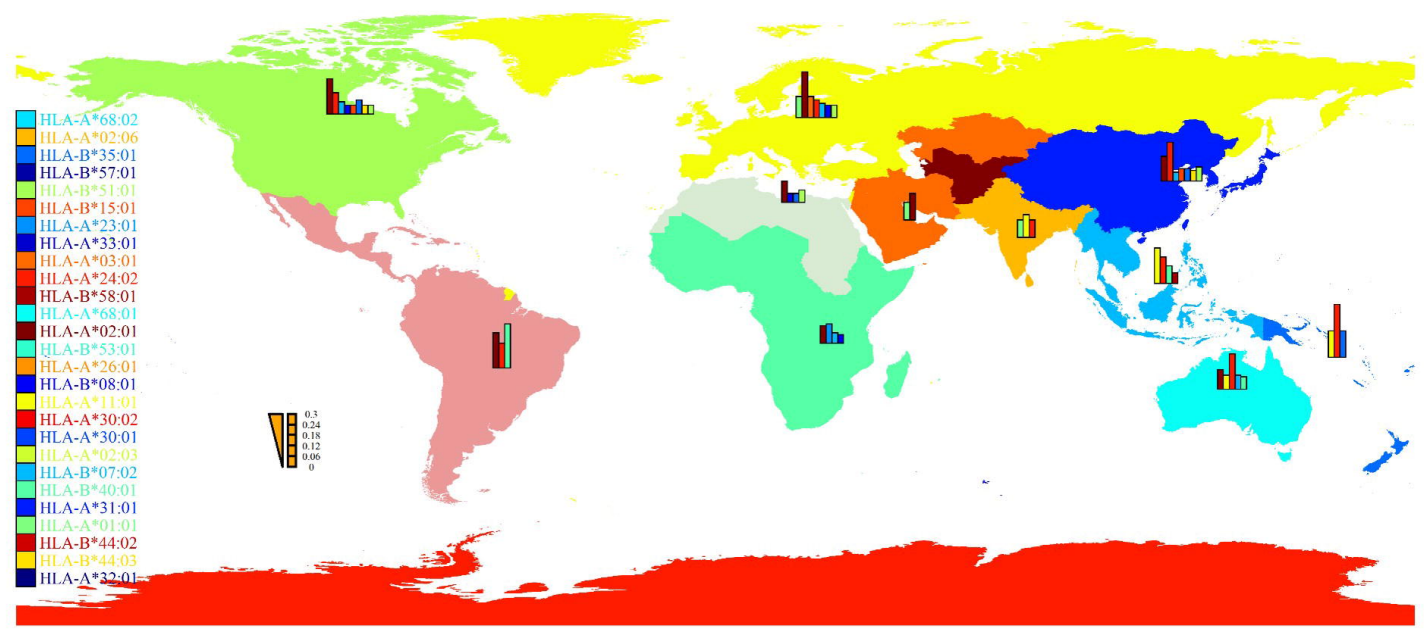

D

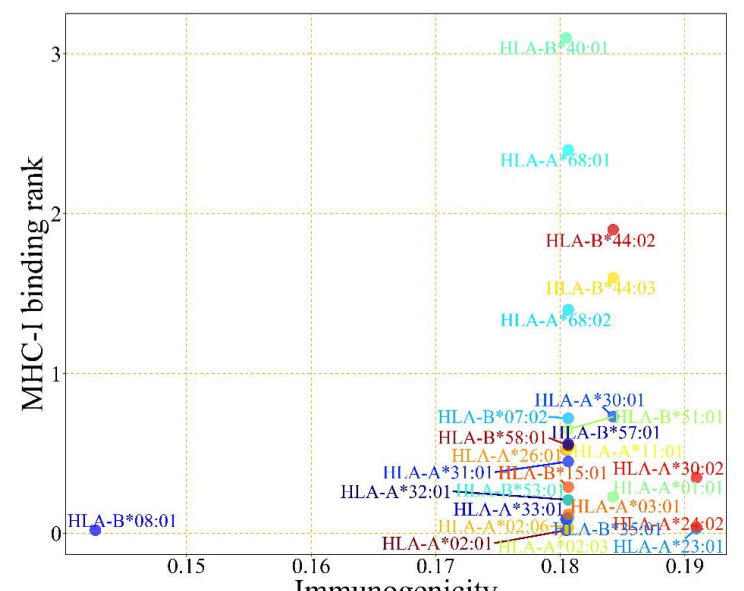

Immunogenicity

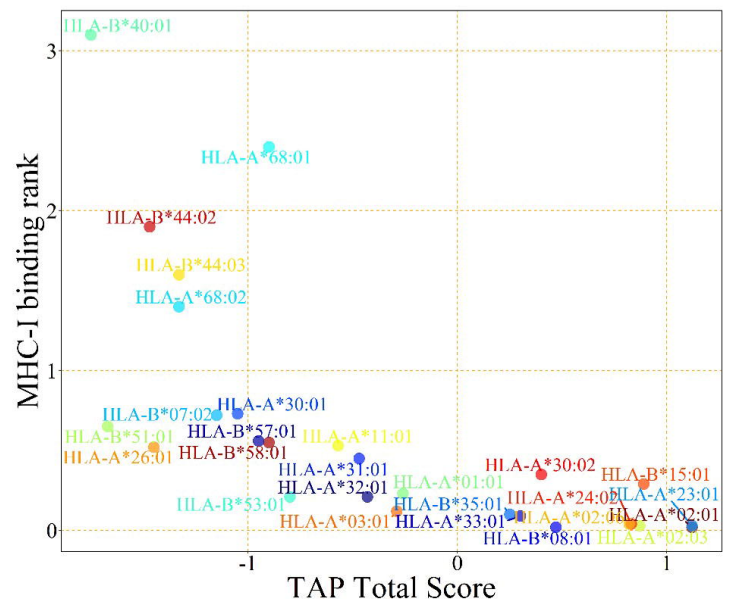

TAP Total Score 